\title{
Percepção Docente sobre o Exame de Suficiência Contábil: Um Estudo em uma Instituição de Ensino Superior do Município de Icó, Ceará-Brasil Carla Natalini Pastor de Souza ${ }^{1}$; Tayssa Vieira Barreto ${ }^{2}$; Antoniel dos Santos Gomes Filhos ${ }^{3}$
}

\begin{abstract}
Resumo: O Exame de Suficiência Contábil tem se tornado fundamental no processo para habilitação do exercício profissional. Diante dessa necessidade, a pesquisa realizada tem o objetivo analisar a importância da contabilidade e do exame de suficiência e as principais dificuldades apresentadas pelos estudantes na perspectiva docente de uma IES. Para fundamentar o trabalho foi realizada uma pesquisa bibliográfica abordando a evolução da ciência contábil, exame de suficiência, profissão contábil e o ensino da contabilidade. É um estudo de natureza básica e exploratório com abordagem qualitativa. O instrumento para a coleta de dados foi um questionário, contendo questões abertas, aplicado aos docentes do curso de Ciências Contábeis de uma IES que ministram disciplinas contempladas no exame de suficiência do CFC. A tabulação se deu através do programa da Microsoft Excel, versão 2010 e a discussão mediante a análise do discurso. Foi constatado que todos os participantes enalteceram que o exame de suficiência contábil é necessário e contribui de maneira significativa na vida profissional como um instrumento de filtragem. Os docentes realçaram como principais entraves dos estudantes a falha na interpretação textual e compreensão da legislação. Dentre as diversas medidas apontadas pelos entrevistados para superar esses entraves, foi dada ênfase às questões que devem possuir o mesmo padrão das solicitadas na prova. Tais dificuldades apresentadas são válidas para ajudar os discentes em sua preparação e posterior aprovação.
\end{abstract}

Palavras-chave: Exame de Suficiência. Contabilidade. Dificuldades.

\section{Teaching Perception on the Accounting Sufficiency Examination: A Study in a Higher Education Institution of the Municipality of Icó in Ceará, Brazil}

\begin{abstract}
The Accounting Sufficiency Examination has as fundamental principle the process of qualification of the professional exercise. Before our consideration, a research carried out had as objective the accounting and the examination of sufficiency and as main difficulties for the students in the educational perspective of an HEI. Bibliographic research on the progress, research, and continuing education of a bibliographical research addresses the science of science, the sufficiency examination, the accounting profession, and the teaching of accounting. It is a basic exploratory study with a qualitative approach. The instrument for data collection was a questionnaire containing the subjects covered by the examination without examination of sufficiency of the CFC. The tabulation was done through the program Microsoft Excel, version 2010 and an analysis by discourse analysis. What was said was that all the participants praised that the accounting sufficiency test is necessary and meaningful in a professional way as a filtering instrument. The teachers emphasized as the main guts of the students an error in the textual interpretation and understanding of the legislation. Among the several measures pointed out by the interviewees to overcome the obstacles, was given in relation to the questions that should be made to the same standard of the requests in the test. Such difficulties are required to assist students in their preparation and subsequent approval.
\end{abstract}

Keywords: Examination of Sufficiency. Accounting. Difficulties.

\footnotetext{
${ }^{1}$ Discente do curso de Ciências Contábeis da Faculdade Vale do Salgado (FVS). E-mail: carlanataline@ hotmail.com

${ }^{2}$ Especialista em Docência do Ensino Superior, e em Gestão Financeira pela FVS. Professora do curso de Ciências Contábeis da Faculdade Vale do Salgado (FVS). E-mail: tayssavieira@fvs.edu.br

${ }^{3}$ Mestre em Educação pela Universidade Federal do Ceará (UFC). Professor da Faculdade Vale do Salgado (FVS). Coordenador do Laboratório Interdisciplinar em Estudos Organizacionais e do Trabalho (LIEOT-FVS). Pesquisador do Laboratório Interdisciplinar em Estudos da Violência no Centro Universitário Dr. Leão Sampaio (LIEV-UNILEÃO). E-mail: antonielsantos@fvs.edu.br
} 


\section{Introdução}

A evolução tecnológica, unida ao processo de globalização, promove o aumento da integração entre países e pessoas do mundo inteiro proporcionando a comercialização e interdependência mercadológica. E nesta realidade emerge a necessidade da Ciência Contábil como instrumento de mensuração, controle e gestão além de um alicerce que embasa a decisão de seus diversos usuários. Por isso, a qualidade do profissional é fator primordial na mediação destes processos e neste cenário evidencia-se o exame de suficiência contábil como importante instrumento de avaliação que almeja analisar o processo de aprendizagem e demonstrar a capacidade e conhecimentos necessários ao exercício da contabilidade.

A relevância da pesquisa reside no fato de apresentar e enaltecer a importância da Ciência Contábil e do Ensino da Contabilidade, como também, os impactos do exame de suficiência contábil, uma vez que tal método de seleção profissional tem apresentado índices elevados de reprovação. Embasado nesta realidade, o questionamento que norteou esta pesquisa foi: quais são as principais dificuldades apresentadas pelos discentes de Ciências Contábeis na percepção docente em relação ao exame de suficiência contábil?

Partindo deste cenário, o objetivo geral da pesquisa foi analisar a importância do exame de suficiência e as principais dificuldades apresentadas pelos estudantes, através da percepção dos docentes de uma Instituição de Ensino Superior do município de Icó no Estado do Ceará. Os objetivos específicos foram: (i) traçar um perfil dos docentes investigados; (ii) elencar as principais dificuldades apresentadas pelos discentes na percepção docente; (iii) descrever a importância da profissão contábil, bem como do exame de suficiência; (iv) apresentar medidas para auxiliar no preparo dos discentes para esse exame.

\section{Fundamentação Teórica}

\section{Evolução da Ciência Contábil}

A Ciência Contábil é considerada uma das mais antigas ciências em virtude de sua função primordial que é o controle do patrimônio de seus usuários (público ou privado) produzindo assim informações que fornecem subsídios para tomada de decisão e melhoria na qualidade de vida dos povos. A contabilidade já se fazia presente desde o início das civilizações, onde já se evidenciava de maneira rudimentar. O homem deixou de ser nômade e começou a 
permanecer em seu espaço mantendo seu patrimônio, como um pastor de ovelhas que utilizava pedras para fazer a contagem de seu rebanho, isto já indicava um controle patrimonial. Preocupando-se com quanto poderia render e qual maneira mais simples de aumentar suas posses, isto já era uma contabilidade (IUDÍCIBUS; MARION; FARIA, 2017). Segundo Coelho (2007, p. 2), “em todos os países do mundo e em todas as épocas, o surgimento e o desenvolvimento da profissão contábil sempre estiveram associados ao desenvolvimento da economia e dos negócios".

No contexto brasileiro, a profissão "guarda-livros" emerge no século XIX, tal expressão caracterizava o atual profissional da contabilidade. Tal caracterização estava vinculada a função do contador que era escrituração e a ordem dos livros mercantis das empresas comerciais. Segundo Conselho Federal de Contabilidade:

Com a publicação do Decreto-Lei n. ${ }^{\circ}$ 9.295, em 27 de maio de 1946, foram sendo criados o Conselho Federal de Contabilidade (CFC) e os Conselhos Regionais de Contabilidade (CRCs). A partir do dispositivo legal, a profissão ganhou regulamento próprio, instituindo-se o princípio básico de que tudo o que envolve a matéria contábil constitui prerrogativa privativa dos profissionais da contabilidade comercial (CFC, 2016, p.27).

A revolução industrial em 1970 veio acarretar uma maior complexidade nas trocas comerciais que foram impulsionadas, graças ao surgimento das fábricas e das máquinas a vapor, como explica Maximiniano (2000). Ainda nesse período, surge a obrigatoriedade das companhias abertas de terem suas demonstrações contábeis padronizadas quanto à sua estrutura e auditadas por auditores independentes (NIYAMA, 2009).

A partir de meados do século XX o desenvolvimento de máquinas, em especial o computador, permitiu a automatização de várias funções da escrituração contábil, trazendo à contabilidade desenvolvimento crescente e um papel importante na vida financeira das pessoas, empresas e cooperativas devido a esse progresso no processo da informação, a fim de atender as exigências sociais e mercadológicas, assim como velocidade da comunicação e preceitos éticos, sendo estes fatores que inspiraram as modificações conceptuais em contabilidade (SÁ, 2005).

Hoje, a profissão contábil é dotada de inúmeras oportunidades e campos de atuação, permitindo-nos escolher entre a pesquisa, a docência, a auditoria, a perícia, entre outras. Podemos reinventar a Contabilidade pela diversidade de suas áreas, pois esta ciência não se reveste de mera abstração teórica, de conhecimento estéril; pelo contrário, temos às mãos um campo fértil em atos criativos e práxis transformadoras (CFC, 2016, p.100). 
Denota-se que a ciência contábil evoluiu muito ao longo dos anos e continua acompanhando proporcionalmente os avanços tecnológicos, melhorando a qualidade de suas informações e transformando o ambiente de seus diversos usuários, evidencia-se, portanto a sua importância no controle do patrimônio e no desenvolvimento de uma região.

\section{Profissão Contábil e o Ensino da Contabilidade}

A contabilidade ao longo de sua história deixou de ser uma profissão de suporte, preocupada apenas em registar fatos e tornou-se uma geradora de informação, assim participando do processo da tomada de decisão, sendo próxima e indispensável ao negócio, exigindo profissionais de elevado nível intelectual, a fim de atender a requisitos de um mercado com maiores complexidades no cenário globalizado em que estes profissionais buscam atuar. Para Pires, Ott e Damacena (2009, p. 157), almejando atender às mudanças ocorridas no ambiente e as expectativas daqueles que demandam seus serviços "o contador deve acompanhar esta evolução, desenvolvendo competências que lhe permitam desempenhar suas atividades de maneira adequada".

Soares (2008) aborda que a profissão contábil está cada vez mais exigindo profissionais com conhecimentos teóricos e práticos, a fim de acompanhar as mudanças decorrentes do próprio desenvolvimento dos negócios e crescimento das empresas. Profissionais esses com vários conhecimentos tanto no mercado nacional quanto internacional, prontos para atender aos interesses de todos seus usuários. Pode-se destacar que várias empresas que se instalam no Brasil têm grandes dificuldades em entender a complexidade da área fiscal e tributária. Assim, as empresas estão à procura desses bons profissionais, conhecedores de assuntos referentes à área contábil, dinâmicos, capazes de discernir coerentemente os dados financeiros e econômicos de suas instituições.

Com a expansão do Ensino Superior no Brasil, houve um aumento significativo no número de instituições ofertando o curso de ciências contábeis e no número de profissionais lançados ao mercado, mas, para Canterle e Favaretto (2008), os desafios impostos por um cenário altamente dinâmico impulsionam a busca de alternativas para oferecer um ensino de qualidade.

O curso superior de Ciências Contábeis e Atuariais foi finalmente reconhecido por meio do Decreto-Lei n. ${ }^{\text {o } 7.988}$, assinado pelo então presidente Getúlio Vargas, no dia 22 de setembro de 1945. O novo dispositivo legal passou a conceder o título de Bacharel em Ciências Contábeis aos concluintes do curso. Com duração de quatro anos, o curso contou, em sua primeira edição, com as disciplinas Contabilidade Geral, 
Organização e Contabilidade Industrial e Agrícola, Organização e Contabilidade Bancária, Organização e Contabilidade de Seguros, Contabilidade Pública e Revisões e Perícia Contábil (CFC, 2016, p.15).

Para Galvão (2016), o exame de suficiência contábil traz na percepção dos alunos uma maior valorização para profissão, bem como seleciona os profissionais mais capacitados, sendo está uma das profissões que mais exigem profissionais qualificados. Pensando nisso, torna-se essencial a participação ativa do aluno no processo de aprendizagem, o mesmo não obtendo apenas conhecimento teórico, mas capacidade intelectual de entender as necessidade e expectativas do mercado, a fim de oferecer crescimento e qualificação profissional. Bezerra e Lucena (2017) salientam como justificativa para a realização do exame, a verificação da aptidão dos recém-graduados.

\section{Exame de Suficiência}

A contabilidade é uma ciência social que vem se desenvolvendo junto com a sociedade em que atua, sofrendo mudanças ao longo do tempo, deixando os limites manuais para acompanhar um cenário cada vez mais tecnológico, tendo como objetivo principal atender as exigências do mercado atuante e promover aos seus usuários informações úteis e oportunas para tomada de decisão. A fim de se adequar as mudanças e, assegurar a seus profissionais, capacidades técnicas para atender as necessidades mercadológicas, é implementado a ela o exame de suficiência contábil (IUDÍCIBUS; MARION; FARIA, 2017).

Madeira, Mendonça e Abreu (2003, p.105) ressaltam a importância desse exame afirmando que:

\footnotetext{
Além de fornecer habilitação profissional para o futuro registro, o exame de suficiência deveria servir como instrumento de apoio às instituições de ensino superior no processo de avaliação e acompanhamento dos cursos, pois através das provas é possível verificar os conteúdos exigidos e compará-los com aqueles ministrados nas faculdades. Desta forma, seria possível identificar as prováveis deficiências, permitindo o aprimoramento dos cursos e, consequentemente, reduzindo as reprovações (MADEIRA; MENDONÇA; ABREU, 2003, p. 105).
}

O Exame de Suficiência Contábil, também conhecido como Exame do Conselho Federal de Contabilidade (CFC) ou Exame do Conselho Regional de Contabilidade é uma prova escrita para avaliar os conhecimentos do estudante de contabilidade, o qual determina se o mesmo está apto ou não para exercer a profissão com o mínimo necessário de conhecimento. O Exame busca suprir algumas deficiências percebidas no ensino contábil e melhor atender as 
necessidades de qualidade no serviço contábil prestado, assegurando assim uma maior qualificação profissional, pois possibilita comprovar se os alunos, ao concluírem a graduação, possuem os conhecimentos médios necessários ao exercício da profissão (CARNEIRO, 2010).

O Exame é administrado por uma comissão formada por contadores indicados pelo próprio CFC e pelo Ibracon. A Resolução CFC n. ${ }^{\circ}$ 1.486/2015 passou a regulamentar, a partir de $1^{\circ}$ de junho de 2015, o Exame de Suficiência como um dos requisitos para a obtenção do Registro Profissional de Contador no Conselho Regional de Contabilidade (CFC, 2016, p.76).

Para Bugarim e Oliveira (2014), o exame como pré-requisito para o registro profissional vem de modo a resguardar os interesses daqueles que utilizam o serviço contábil e proteger a sociedade contra os menos capacitados. Dos assuntos abordados na prova, no Edital do Exame de Suficiência 2018.2, destacam-se:

PROVA PARA BACHAREL EM CIÊNCIAS CONTÁBEIS: a) Contabilidade Geral; b) Contabilidade de Custos; c) Contabilidade Aplicada ao Setor Público; d) Contabilidade Gerencial; e) Controladoria; f) Noções de Direito e Legislação Aplicada; g) Matemática Financeira e Estatística; h) Teoria da Contabilidade; i) Legislação e Ética Profissional; j) Princípios de Contabilidade e Normas Brasileiras de Contabilidade; k) Auditoria Contábil; 1) Perícia Contábil; m) Língua Portuguesa Aplicada (CFC, 2018, p. 12).

A prova é realizada duas vezes ao ano conforme a disposição do Conselho Federal de Contabilidade (CFC), onde o total mínimo de acertos para aprovação corresponde a $50 \%$ da prova, conforme os artigos $3^{\circ}$ e $4^{\circ}$ da Resolução CFC n ${ }^{\circ} 1.486 / 2015$. Leite (2005) enfatiza que o exame deveria, também, ser utilizado como parâmetro às IES, na forma de indicadores, a fim de melhorar a qualidade dos serviços prestados.

No que se refere aos conceitos e objetivos do Exame de Suficiência, a Resolução CFC $\mathrm{n}^{\circ} 1.486 / 15$ assim apresenta:

\begin{abstract}
Art. $1^{\circ}$ Exame de Suficiência é a prova de equalização destinada a comprovar a obtenção de conhecimentos médios, consoante os conteúdos programáticos desenvolvidos no curso de Bacharelado em Ciências Contábeis. Parágrafo único. O Exame de Suficiência, que visa à obtenção de registro na categoria Contador, pode ser prestado pelos bacharéis e estudantes do último ano letivo do curso de Ciências Contábeis. Art. $2^{\circ}$ A aprovação em Exame de Suficiência constitui um dos requisitos para a obtenção de registro profissional em Conselho Regional de Contabilidade (CFC $1486 / 15)$.
\end{abstract}

É de competência do Conselho Federal de Contabilidade a responsabilidade de contratar, elaborar e divulgar o conteúdo das respectivas áreas que serão exigidas nos exames, como requisito para concessão do registro profissional e aqueles alunos que obtiverem sua aprovação no exame, após divulgação do resultado no diário oficial da união, podem inscreverem-se no 
Conselho Regional de Contabilidade do seu estado para obter a licença para exercer a profissão de contador, sem prazo limite fixado para tal. Conforme escreve Buarque (2005, p. 56), "não há universidade sem avaliação, porque sem ela não há qualidade, e sem qualidade não se consegue sucesso pessoal nem capacidade de transformação social".

De acordo com os resultados estatísticos do CFC (2018), observa-se ainda um índice elevado de reprovação nas diversas regiões, tais como apresenta a figura abaixo.

Figura 01: Resultado Final do Exame de Suficiência de 2011.1 a 2017.2

\begin{tabular}{|c|c|c|c|c|c|c|c|c|}
\hline \multicolumn{9}{|c|}{ CONTADOR } \\
\hline Exame & $\begin{array}{c}\text { Total } \\
\text { Inscritos }\end{array}$ & $\begin{array}{c}\text { Total } \\
\text { Presentes }\end{array}$ & $\begin{array}{c}\text { Total } \\
\text { Aprovados }\end{array}$ & $\begin{array}{c}(\%) \\
\text { Aprovados }\end{array}$ & $\begin{array}{c}\text { Total } \\
\text { Reprovados }\end{array}$ & $\begin{array}{c}(\%) \\
\text { Reprovados }\end{array}$ & $\begin{array}{c}\text { Total } \\
\text { Ausentes }\end{array}$ & $\begin{array}{c}(\%) \\
\text { Ausentes }\end{array}$ \\
\hline $10 / 2011$ & 14255 & 13383 & 4130 & $30.86 \%$ & 9253 & $69.14 \%$ & 872 & $6.12 \%$ \\
\hline $20 / 2011$ & 19690 & 18675 & 10886 & $58.29 \%$ & 7789 & $41.71 \%$ & 1015 & $5.15 \%$ \\
\hline $10 / 2012$ & 26316 & 24774 & 11705 & $47.25 \%$ & 13069 & $52.75 \%$ & 1542 & $5.86 \%$ \\
\hline $20 / 2012$ & 32003 & 29226 & 7613 & $26.05 \%$ & 21613 & $73.95 \%$ & 2777 & $8.68 \%$ \\
\hline $10 / 2013$ & 37229 & 33708 & 12000 & $35.6 \%$ & 21708 & $64.4 \%$ & 3521 & $9.46 \%$ \\
\hline $20 / 2013$ & 40477 & 36833 & 15891 & $43.14 \%$ & 20942 & $56.86 \%$ & 3644 & $9 \%$ \\
\hline $10 / 2014$ & 43144 & 38116 & 18824 & $49.39 \%$ & 19292 & $50.61 \%$ & 5028 & $11.65 \%$ \\
\hline $20 / 2014$ & 37066 & 32568 & 13591 & $41.73 \%$ & 18977 & $58.27 \%$ & 4498 & $12.14 \%$ \\
\hline $10 / 2015$ & 43616 & 38023 & 20715 & $54.48 \%$ & 17308 & $45.52 \%$ & 5593 & $12.82 \%$ \\
\hline $20 / 2015$ & 43376 & 38022 & 5580 & $14.68 \%$ & 32442 & $85.32 \%$ & 5354 & $12.34 \%$ \\
\hline $10 / 2016$ & 48043 & 41987 & 17576 & $41.86 \%$ & 24411 & $58.14 \%$ & 6056 & $12.61 \%$ \\
\hline $20 / 2016$ & 47031 & 40879 & 8948 & $21.89 \%$ & 31931 & $78.11 \%$ & 6152 & $13.08 \%$ \\
\hline $10 / 2017$ & 54051 & 46949 & 11860 & $25.26 \%$ & 35089 & $74.74 \%$ & 7102 & $13.14 \%$ \\
\hline $20 / 2017$ & 52663 & 44557 & 12041 & $27.02 \%$ & 32516 & $72.98 \%$ & 8106 & $15.39 \%$ \\
\hline Total geral: & 538960 & 477700 & 171360 & $35.87 \%$ & 306340 & $64.13 \%$ & 61260 & $11.37 \%$ \\
\hline
\end{tabular}

Fonte: Dados CFC

Analisando o resultado da média geral dos exames de 2011.1 a 2017.2, percebe-se que apenas $35.87 \%$ dos candidatos ao realizarem o exame obtiveram um resultado positivo, conquistando a aprovação. Percentual de reprovados ficou em torno de $64.13 \%$, ficando assim identificado que mais da metade dos alunos ao realizarem o exame saem reprovados e que a quantidade de alunos ausentes teve como média geral $11.37 \%$, porem da primeira edição em 2011 até a última em 2017 esse número se mostrou crescente. 


\section{Metodologia}

Caracteriza-se por ser um estudo de natureza básica e exploratório com abordagem qualitativa. Quanto ao estudo exploratório, para Prodanov e Freitas (2013) trata-se de uma pesquisa que possui um planejamento que estuda o tema em várias perspectivas e aspectos. A abordagem qualitativa conforme Gerhardt e Silveira (2009) é aquela que não se preocupa com a tabulação numérica dos dados obtidos.

O instrumento para a coleta dos dados foi à aplicação de um questionário estruturado com questões abertas respondidas pelos docentes do curso de Ciências Contábeis de uma IES. Atualmente, existem 9 professores que ministram as disciplinas contempladas no exame do CFC dos quais 8 responderam a pesquisa. Participaram da pesquisa os docentes do Curso de Ciências Contábeis de uma IES localizada na cidade de Icó/CE que ministram as disciplinas cobradas no Exame de Suficiência de 2018. Não participaram da pesquisa, os professores dos demais cursos e docentes que ministram disciplinas que não sejam contempladas no exame.

Para a realização da tabulação dos dados da aplicação do questionário e da discussão do trabalho foi utilizado o Excel versão 2010 e a análise se deu a partir da análise do conteúdo que segundo Gerhardt e Silveira (2009) é uma técnica metodológica que apresenta objetividade e sistematização. Visando viabilizar o processo do estudo de campo, quanto aos aspectos éticos o estudo foi norteado pelas as diretrizes da resolução $n^{\circ}$ 510/2016, do Conselho Nacional de Saúde-CNS.

\section{Análise dos Resultados}

A seguir, serão analisados e discutidos os resultados da pesquisa:

Tabela 1: Caracterização quanto o perfil dos docentes investigados

\begin{tabular}{c|c}
\hline \multirow{4}{*}{ Qual a sua formação acadêmica? } & E1: Ciências Contábeis. \\
\cline { 2 - 2 } & E2: Direito. \\
\cline { 2 - 2 } & E3: Ciências Contábeis. \\
\cline { 2 - 2 } & E4: Matemática e Economia. \\
\cline { 2 - 2 } Qual a disciplina que você ministra atualmente & E6: Ciências Contábeis e Direito. \\
\cline { 2 - 2 } na instituição? & E7: Ciências Contábeis. \\
\cline { 2 - 2 } & E8: Ciências Contábeis. \\
\cline { 2 - 2 } & \\
\cline { 2 - 2 } & E1: Perícia Contábil. \\
\cline { 2 - 2 } & E3: Controdução ao Dilidade pública. \\
\cline { 2 - 2 } & E4: Matemática financeira. \\
\hline
\end{tabular}




\begin{tabular}{l|c}
\hline \multirow{4}{*}{ Qual o seu tempo de atuação na instituição? } & E5: Contabilidade Gerencial. \\
\cline { 2 - 2 } & E6: Contabilidade Comercial. \\
\hline & E7: Contabilidade Tributária. \\
\cline { 2 - 2 } & E1: 3 anos e 2 meses. \\
\cline { 2 - 2 } & E2: 6 anos. \\
\cline { 2 - 2 } & E3: Mais de 10 anos. \\
\cline { 2 - 2 } & E4: 13 anos. \\
\cline { 2 - 2 } & E5: 1 ano e 6 meses. \\
\cline { 2 - 2 } & E6: 2 anos. \\
\cline { 2 - 2 } & E7: 5 anos. \\
\hline
\end{tabular}

Fonte: Dados da Pesquisa (2018)

A tabela 01 apresenta o perfil dos participantes da pesquisa evidenciando que a maioria dos investigados possui graduação em Ciências Contábeis (05 professores). Seguidos de Direito, Matemática, História e Economia.

Em relação às disciplinas ministradas pelos professores atualmente foram destacadas: Contabilidade Comercial, Contabilidade Gerencial, Contabilidade Pública, Perícia, Contabilidade Tributária, Direito Tributário, Introdução ao Direito, Ética e Matemática Financeira. Matérias às quais estão em acordo com as solicitadas no exame. Este resultado vai ao encontro ao que diz no edital do Exame de Suficiência 2018.2 no que se refere às disciplinas solicitadas na prova. Pires, Ott e Damacena (2009) acreditam que para atender as mudanças ocorridas no cenário contábil é necessário que o contador desenvolva novas competências, sendo que estas também sejam contempladas nos exames de suficiência.

Tabela 2: Importância da profissão contábil e do exame de suficiência

\begin{tabular}{|c|c|}
\hline \multirow{8}{*}{$\begin{array}{l}\text { De que maneira você reconhece a } \\
\text { importância da Ciência Contábil? }\end{array}$} & $\begin{array}{l}\text { E1: Controle social, auxílio à tomada de decisão, geração } \\
\text { de valor convertido em benfeitoria à sociedade. }\end{array}$ \\
\hline & E2: Desenvolvimento institucional e do país. \\
\hline & E3: Vida financeira e social. \\
\hline & E4: Patrimônio. \\
\hline & E5: Administração econômica e gestão do negócio. \\
\hline & E6: Ferramenta técnica na busca de novos caminhos. \\
\hline & $\begin{array}{l}\text { E7: Desenvolvimento do país e crescimento e sucesso } \\
\text { empresarial. }\end{array}$ \\
\hline & E8: Tomada de decisão. \\
\hline \multirow{6}{*}{$\begin{array}{l}\text { Qual a sua percepção com relação à } \\
\text { importância do exame de suficiência } \\
\text { contábil? }\end{array}$} & $\begin{array}{l}\text { E1: Imprescindível, afunilar o nível profissional no } \\
\text { mercado de trabalho. }\end{array}$ \\
\hline & E2: Importante instrumento na filtragem de profissionais. \\
\hline & $\begin{array}{l}\text { E3: Necessário, tendo em vista credenciar e habilitar o } \\
\text { profissional. }\end{array}$ \\
\hline & E4: Controle de qualidade profissional. \\
\hline & E5: Importante para avaliar os bacharéis e as instituições. \\
\hline & $\begin{array}{l}\text { E6: Importante para entrada de trabalho de bons } \\
\text { profissionais. }\end{array}$ \\
\hline
\end{tabular}




\begin{tabular}{|c|c|}
\hline & E7: Valorização profissional. \\
\hline & $\begin{array}{l}\text { E8: Muito importante na seleção do mercado da atuação } \\
\text { profissional. }\end{array}$ \\
\hline \multirow{8}{*}{$\begin{array}{c}\text { Como você avalia a importância do ensino da } \\
\text { contabilidade? }\end{array}$} & $\begin{array}{l}\text { E1: Importante para todas as pessoas saberem administrar } \\
\text { seus rendimentos. }\end{array}$ \\
\hline & $\begin{array}{c}\text { E2: Indispensável à formação acadêmica e profissional e } \\
\text { uma formação de qualidade. }\end{array}$ \\
\hline & $\begin{array}{l}\text { E3: Necessário para o desenvolvimento financeiro e social } \\
\text { das empresas e pessoas. }\end{array}$ \\
\hline & E4: Construção profissional. \\
\hline & $\begin{array}{l}\text { E5: Além da formação técnica, integral da profissão as } \\
\text { exigências do mercado de trabalho. }\end{array}$ \\
\hline & E6: Alcançar um excelente resultado. \\
\hline & E7: Eficaz e eficiente. \\
\hline & E8: Importante, indispensável na economia do país. \\
\hline
\end{tabular}

Fonte: Dados da Pesquisa (2018)

A tabela 02 possui enfoque na importância da profissão contábil e no exame de suficiência contábil. Diante dos dados coletados, pode-se constatar que os entrevistados reconhecem a importância desta ciência na tomada de decisão, no desenvolvimento social e institucional como também ferramenta de controle e gestão patrimonial e financeira. Fatores como desenvolvimento, crescimento e sucesso também foram mencionados como sendo associados à consequência da presença da ciência contábil no meio empresarial, social e nacional, evidenciando-se assim sua importância para o meio. Este resultado vai ao encontro do que diz Coelho (2007) sobre o desenvolvimento da profissão contábil sempre estar ligada ao desenvolvimento da economia e dos negócios. Iudícibus, Marion e Faria (2017), também embasam este dado quando salientam que a função primordial da contabilidade é o controle e gestão do patrimônio de seus usuários.

A percepção dos participantes em relação à importância do exame de suficiência contábil demonstrou uma unanimidade em relação a sua necessidade, importância e contribuição, não havendo opiniões contrárias à sua aplicação, nem a citação de malefícios do exame. Carneiro (2010) entende que o exame procura suprir falhas percebidas, bem como comprovar se os alunos estão aptos para exercício profissional, contribuindo para qualidade no serviço contábil prestado.

Foi evidenciada também a atuação do exame como importante meio de seleção e filtragem de profissionais que atuarão no mercado a nível de qualidade profissional. Os demais docentes salientaram a contribuição para o credenciamento e habilitação dos profissionais, enaltecendo-o ainda como sendo meio de valorização profissional para classe, opiniões as quais 
convergem entre si, tendo em vista que busca habilitar e filtrar os menos preparados. Corroborando assim com Buarque (2005) que considera que sem avaliação não há qualidade.

O ensino da contabilidade foi destacado como indispensável para construção profissional que necessita de uma formação com qualidade para atender as exigências mercadológicas e nacionais de maneira eficaz contribuindo para um excelente resultado. Tal conclusão vai ao encontro do que Soares (2008) já destacava sobre a necessidade crescente e contínua de bons profissionais para atuarem tanto no mercado nacional como internacional. $\mathrm{O}$ ensino foi destacado também como essencial para a economia do país e para o desenvolvimento social e financeiro. Pode-se observar uma relação entre a importância do ensino da contabilidade e o exame de suficiência (quesito anterior) como filtro, uma vez que a ciência contábil contribui diretamente no desenvolvimento do país e para isso carece de profissionais habilitados na execução de sua profissão.

Tabela 3: Principais dificuldades para o exame de suficiência na percepção docente e medidas para auxiliar no preparo

De maneira geral, quais as principais dificuldades apresentadas pelos alunos no que tange o exame de suficiência?

E1: Interpretação e análise de questões. E2: Extensão da prova, complexidade e tempo. E3: Dificuldade de leitura e interpretação de texto.

E4: Competência ou habilidade em leitura e interpretação.

E5: Adaptação ao modelo de questões. E6:

E7: Assimilação do conteúdo e prática efetiva do estudo.

E8: Interpretação de texto.

E1: Entendimento da legislação. E2: Linguagem específica. E3: Leitura e Interpretação de texto. E4: Falta de base.

Dentro de sua disciplina, quais principais dificuldades apresentadas pelos estudantes?

\begin{tabular}{c} 
E1: Entendimento da legislação. \\
E2: Linguagem específica. \\
\hline E3: Leitura e Interpretação de texto. \\
\hline E4: Falta de base. \\
\hline $\begin{array}{c}\text { E5: Compreensão sobre legislação em sua } \\
\text { contextualização. }\end{array}$ \\
\hline E6: Compreensão do texto. \\
\hline $\begin{array}{c}\text { E7: Comprometimento e reserva de tempo para } \\
\text { estudar. }\end{array}$ \\
\hline E8: Cálculos e interpretação das leis. \\
\hline
\end{tabular}

\begin{tabular}{c|c}
\hline \multirow{4}{*}{$\begin{array}{c}\text { Enquanto professor, quais as medidas que } \\
\text { poderiam ser adotadas para auxiliar no preparo e } \\
\text { posterior aprovação dos estudantes? }\end{array}$} & $\begin{array}{c}\text { E1: Estudo de casos e leitura e interpretação de } \\
\text { questões. }\end{array}$ \\
\cline { 2 - 2 } \begin{tabular}{c} 
E2: Abordagem de questões. \\
\cline { 2 - 2 } $\begin{array}{c}\text { E4: Aulas focando os conteúdos mais cobrados e } \\
\text { avaliações no modelo das questões do exame. }\end{array}$ \\
\cline { 2 - 2 }
\end{tabular} & $\begin{array}{c}\text { E5: Testes, simulados e aulas de revisão. } \\
\text { problemas práticos de contabilidade. }\end{array}$ \\
\cline { 2 - 2 } & E6: Trabalhar a leitura. \\
\cline { 2 - 2 } & E7: Aulas íntegras, revisões, simulados, etc. \\
\cline { 2 - 2 }
\end{tabular}




\begin{tabular}{|c|c|}
\hline \multirow{8}{*}{$\begin{array}{l}\text { Como você justifica o índice de reprovação } \\
\text { apresentado pelo conselho federal de } \\
\text { contabilidade? }\end{array}$} & E1: Falta de estudo, dedicação e foco. \\
\hline & E2: Complexidade crescente da prova. \\
\hline & $\begin{array}{l}\text { E3: Questões difíceis induzindo ao erro e } \\
\text { preocupar-se apenas ao final do curso. }\end{array}$ \\
\hline & E4: Não estudar o necessário. \\
\hline & $\begin{array}{l}\text { E5: Falta de preparação específica, dedicação ao } \\
\text { curso ou próprio ensino que não contemple todas } \\
\text { competências. }\end{array}$ \\
\hline & $\begin{array}{l}\text { E6: Não entender que o processo da educação é uma } \\
\text { eterna construção. }\end{array}$ \\
\hline & E7: Falta de comprometimento com os estudos. \\
\hline & E8: Baixa qualidade do ensino e falta de base. \\
\hline
\end{tabular}

Fonte: Dados da Pesquisa (2018)

Em relação às principais dificuldades apresentadas pelos alunos no que se refere ao exame de suficiência ficou evidenciado a falta de habilidade com leitura, ocorrendo assim a dificuldade de compreensão e interpretação de texto. Aparecem ainda dificuldades relacionadas à adaptação ao modelo de avalição, elencando-se fatores como extensão da prova, crescente complexidade e tempo. Apenas um participante não se pronunciou a respeito deste questionamento. Diante desta realidade, comprova-se a necessidade de serem trabalhadas interpretações textuais, bem como análise e prática de questões do exame correlacionando ao tempo cobrado na prova.

No quesito posterior foram apresentadas, na percepção docente, as principais dificuldades apresentadas pelos alunos dentro de suas disciplinas. Dentre os entraves mais citados estão a dificuldade de interpretação textual e entendimento da legislação. Comprometimento, cálculos, falha na base e tempo para estudar foram também diagnosticados pelos entrevistados (em menor escala). Denota-se que a compreensão textual foi considerada predominante conforme apresenta também o questionamento anterior. Segundo Carneiro (2010) O exame buscar suprir deficiências essas deficiências percebidas no ensino, assegurando conhecimentos médios necessários ao exercício profissional.

O tópico posterior tratou sobre as medidas que poderiam ser adotadas para auxiliar na preparação destes alunos. Foram destacadas: trabalhar questões semelhantes (citada 4 vezes), leitura (3), simulados (3), revisões (3), estudo de caso (1), avaliações semelhantes (1), aulas com ênfase nos principais conteúdos cobrados no exame (1) e resolução de problemas práticos. Observa-se uma relação deste tópico com o questionamento anterior para sanar entraves na realização da prova, tais como trabalhar leituras com mais frequência e assim aguçar a interpretação textual e, consequentemente, a compreensão da legislação e dos cálculos. Leite 
(2005) enfatiza que o exame pode servir como parâmetro para IES melhorar a qualidade dos serviços prestados.

Os docentes atribuem o índice de reprovação no exame aos seguintes fatores: falta de estudo (citado 4 vezes), complexidade da prova (3), falta de dedicação (3), baixa qualidade do ensino (1), falta de base (1), não compreender o processo construtivo da educação (1) e a preocupação do aluno apenas com a conclusão do curso (1). As dificuldades tanto no exame quanto nas disciplinas ministradas ficaram evidenciadas como sendo problema de leitura por parte dos alunos, estes tendo dificuldades neste tipo de competência. As causas ficaram atribuídas ao baixo comprometimento do aluno no processo ativo e contínuo da construção do conhecimento e as medidas para solucionar estas deficiências apareceram como mudanças na maneira de transmitir e cobrar conhecimento dos discentes por parte docente. Madeira, Mendonça e Abreu (2003) diz que o exame além de servir de apoio ás instituições no processo de avaliação e acompanhamento do curso, permitindo a identificação de deficiências, podendo melhorar seus serviços e, consequentemente reduzir as reprovações.

\section{Considerações Finais}

Dada à relevância do trabalho de conclusão de curso, se almejou analisar o índice de reprovação na região nordeste e principais impactos e a percepção docente de uma IES sobre tal realidade.

Os objetivos sugeridos foram alcançados constatando-se que estes profissionais reconhecem a importância da Ciência Contábil na tomada de decisão de seus usuários, no desenvolvimento social e institucional, como também ferramenta de controle gerencial e financeiro. De maneira unânime, os participantes salientaram que o exame de suficiência contábil é necessário e contribui de maneira significativa na vida profissional. Foi demonstrado também que o exame é uma ferramenta de filtragem dos profissionais que atuarão no mercado de trabalho. Denota-se uma relação entre o ensino da contabilidade e o exame de suficiência, uma vez que a ciência contábil é indispensável no desenvolvimento do país e, portanto, necessita-se de profissionais habilitados.

Os docentes destacaram como principais dificuldades observadas nos estudantes a falha na interpretação textual e compreensão da legislação. Em menor escala, também foram apresentadas falta de comprometimento, os cálculos, problemas na base dos estudos e tempo 
disponível para estudar. O entrave mais destacado, na percepção docente, que justifica o índice de reprovação no exame, foi a falha na interpretação textual, o que acarreta os demais fatores.

Dentre as diversas medidas apontadas pelos docentes, os participantes destacaram trabalhar questões no mesmo padrão das solicitadas no exame como um canal para solucionar as dificuldades de seus estudantes.

Portanto, evidencia-se a importância, impacto e aplicabilidade do ensino da contabilidade e do exame de suficiência contábil. Tais dificuldades apresentadas são válidas para ajudar os discentes em sua preparação e posterior aprovação. No entanto, é válido destacar que o índice de reprovação é considerado alto para as diversas regiões (conforme dados do CFC) e o presente estudo sugere uma pesquisa mais aprofundada nos fatores que influenciam as diferentes unidades da federação.

\section{Referências}

BEZERRA, H. A. G.; LUCENA, W. G. L. Exame de Suficiência Contábil: uma análise dos conteúdos de formação profissional nas provas de 2011 a 2015. Revista Brasileira de Contabilidade. $\mathrm{N}^{\mathrm{o}} 226$, jul/ago, 2017.

BRASIL. Resolução CFC n ${ }^{\circ}$ 1.486, de 15 de maio de 2015. Regulamenta o Exame de Suficiência como requisito para obtenção de Registro Profissional em Conselho Regional de Contabilidade (CRC). Diário Oficial da União, Brasília, DF: 2015. Disponível em: < http://www.normaslegais.com.br/legislacao/resolucao-cfc-1486-2015.htm>. Acesso em: 13 ago. 2018.

BUARQUE, C. A refundação da universidade. Brasília, DF: ABMES Ed., 2005. Disponível em: <https://abmes.org.br/arquivos/publicacoes/Cristovam_Buarque.pdf>. Acesso em: 22 ago. 2018.

BUGARIM, M.; OLIVEIRA, O. A Evolução da Contabilidade no Brasil: Legislações, órgão de Fiscalização, Instituições de Ensino e Profissão. In: XI Simpósio de Excelência em Gestão e Tecnologia - SEGet. Resende/RJ: ANGRAD, 2014.

CANTERle, N. M. G.; FAVARETTO, F. Proposta de um modelo referencial de gestão de indicadores de qualidade na instituição universitária. 2008. Disponível em: 〈www.scielo.br>. Acesso em: 20 mai. 2018.

CARNEIRO, J. CFC - Regulamenta o Exame de Suficiência. CRCSC Jornal. Set. /Out. 2010.

CFC. CFC 70 anos de contabilidade. Brasília: 2016. Disponível em: < https://cfc.org.br/wpcontent/uploads/2016/08/70anos-cfc.pdf>. Acesso em: 30 ago. 2018.

CFC. Edital CFC 2018. Disponível em: <https://cfc.org.br/exame-de-suficiencia-anteriores/2o-examede-suficiencia-de-2018/>. Acesso em: 15 mai. 2018.

CFC. Resultado final por exame. 2018. Disponível em: <https://cfc.org.br/wpcontent/uploads/2017/11/Resultadofinalporexame.pdf >. Acesso em: 15 mai. 2018. 
COELHO, C. U. F. O técnico em contabilidade e o mercado de trabalho: contexto histórico, situação atual e perspectivas. 2007. Disponível em: <https://www.sp.senac.br/downloads/ 108_contabilidade.pdf >. Acesso em: 30 mai. 2018.

GALVÃO, N. M. S. Percepção dos Contadores sobre o Exame de Suficiência do Conselho Federal de Contabilidade. Revista Catarinense de Ciência Contábil. Florianópolis, v. 15, n.16, maio/agosto, 2016.

GERHARDT, T. E.; SILVEIRA, D. T. Métodos de pesquisa. $1^{a}$ ed. Porto Alegre: Editora da UFRGS, 2009. Disponível em:< http://www.ufrgs.br/cursopgdr/downloadsSerie/derad005.pdf >. Acesso em: 15 mai. 2018.

IUDÍCIBUS, S.; MARION, J. C.; FARIA, A. C. Introdução à teoria da contabilidade. 6 ed. São Paulo: Atlas, 2017.

LEITE, C. A evolução das Ciências Contábeis no Brasil. Rio de Janeiro: Editora FGV, 2005.

MADEIRA, G. J.; MENDONÇA, K. F. C.; ABREU, S. M. A disciplina teoria da Contabilidade nos exames de suficiência e provão. Contabilidade Vista \& Revista. V. 14, edição especial, p.103-122, 2003.

MAXIMIANO, A. C. A. Teoria Geral da Administração: da escola científica à competitividade na economia globalizada. $2^{a}$ ed. São Paulo: Atlas, 2000.

NIYAMA, J. K. Contabilidade Internacional. São Paulo: Atlas. 2009.

PIRES, C. B.; OTT; DAMACENA, C. "Guarda - Livros" ou "Parceiros de Negócios"? Uma análise do perfil profissional requerido pelo mercado de trabalho para contadores na região metropolitana de Porto Alegre (RMPA). Revista Contabilidade Vista \& Revista. V. 20, 157-187, 2009.

PRODANOV, C. C.; FREITAS, E. C. Metodologia do Trabalho Científico: Métodos e Técnicas da Pesquisa e do Trabalho Acadêmico. $2^{\mathrm{a}}$ ed. Rio Grande do Sul: Feevale, 2013. 51 p.

SÁ, A. L. Pré História Contábil Brasileira. Portugal: 2005. Disponível em: <antoniolopesdesa.com.br>. Acesso em: 09 set. 2018.

SOARES, M. J. Gestão tributária: um estudo sobre a pratica de planejamento tributário adotado por industrias paranaenses. Curitiba: 2008. Disponível em: <http://www.ppgcontabilidade. ufpr.br/system/files/documento/Dissertações/D011.pdf>. Acesso em: 16 set. 2018.

\section{Como citar este artigo (Formato ABNT):}

SOUZA, Carla Natalini Pastor de; BARRETO, Tayssa Vieira; GOMES FILHO, Antoniel dos Santos Gomes. Percepção Docente sobre o Exame de Suficiência Contábil: Um Estudo em uma Instituição de Ensino Superior do Município de Icó, Ceará-Brasil. Id on Line Rev.Mult. Psic., 2019, vol.13, n.43, p. 280-294. ISSN: 1981-1179.

Recebido: 23/11/2018;

Aceito: $24 / 11 / 2018$ 